\title{
Pathophysiological Analysis of the Progression of Hepatic Lesions in STAM Mice
}

\author{
T. SAITO ${ }^{1}$, M. MURAMATSU ${ }^{1}$, Y. ISHII ${ }^{1}$, Y. SAIGO ${ }^{1}$, T. KONUMA ${ }^{1}$, Y. TORINIWA ${ }^{1}$, \\ K. MIYAJIMA ${ }^{2}$, T. OHTA ${ }^{1}$ \\ ${ }^{1}$ Biological/Pharmacological Research Laboratories, Central Pharmaceutical Research Institute, \\ Japan Tobacco, Takatsuki, Osaka, Japan, ${ }^{2}$ Toxicology Research Laboratories, Central \\ Pharmaceutical Research Institute, Japan Tobacco, Hadano, Kanagawa, Japan
}

Received January 5, 2017

Accepted February 16, 2017

On-line July 18, 2017

\section{Summary}

Nonalcoholic steatohepatitis (NASH) is a current health issue since the disease often leads to hepatocellular carcinoma; however, the pathogenesis of the disease has still not been fully elucidated. In this study, we investigated the pathophysiological changes observed in hepatic lesions in STAM mice, a novel NASH model. STAM mice, high fat-diet (HFD) fed mice, and streptozotocin (STZ) treated mice were prepared, and changes over time, such as biological parameters, mRNA expression, and histopathological findings, were evaluated once animal reached 5,7 , and 10 weeks of age. STZ mice presented with hyperglycemia and an increase in oxidative stress in immunohistochemical analyses of Hexanoyl-lysine: HEL from 5 weeks, with fibrosis in the liver also being observed from 5 weeks. HFD mice presented with hyperinsulinemia from 7 weeks and the slight hepatosteatosis was observed at 5 weeks, with changes significantly increasing until 10 weeks. STAM mice at 10 weeks showed significant hepatic changes, including hepatosteatosis, hypertrophic hepatocytes, and fibrosis, indicating pathological changes associated with NASH. These results suggested that the increase in oxidative stress with hyperglycemia triggered hepatic lesions in STAM mice, and insulin resistance promoted lesion formation with hepatic lipid accumulation. STAM mice may be a useful model for elucidating the pathogenesis of NASH with diabetes.

\section{Key words}

Diabetes • NASH • STAM mice

\section{Corresponding author}

T. Ohta, Biological/Pharmacological Research Laboratories, Central Pharmaceutical Research Institute, Japan Tobacco Inc., 1-1 Murasaki-cho, Takatsuki, Osaka 569-1125, Japan. E-mail: takeshi.ota@jt.com

\section{Introduction}

Nonalcoholic fatty liver disease (NAFLD) is presently recognized as the most common chronic liver disease and a major hepatic health issue in the world (Clark 2006, de Alwis and Day 2008, Zelber-Sagi et al. 2006). NAFLD is associated with obesity, diabetes, insulin resistance, dyslipidemia, and hypertension (de Alwis and Day 2008, Falck-Ytter et al. 2001).

NAFLD presents with fatty liver pathology, including simple steatosis, nonalcoholic steatohepatitis (NASH), and cirrhosis, with $4-22 \%$ of NAFLD patients developing hepatocellular carcinoma (Ertle et al. 2011, Greenfield et al. 2008). However, the pathogenesis of NAFLD and the progression to fibrosis and chronic liver disease remains poorly defined, and effective pharmacological therapies, in particular for NASH, have not been approved. The leading hypothesis for this liver disease is the two-hit model (Day and James 1998). The first hit is initial metabolic changes, such as hyperglycemia, insulin resistance, hyperlipidemia, and lipid accumulation in the liver, leading to steatosis. The second hit including genetic and environmental factors triggers the progression to more severe liver pathologies. 
To elucidate the complicated features of NAFLD/NASH, animal models offer important information. As NAFLD/NASH animal models, ob/ob mice, db/db mice, KK-Ay mice, Zucker fatty (ZF) rats, and Spontaneously Diabetic Torii (SDT) fatty rats develop spontaneous hepatic steatosis based on insulin resistance and obesity (Ishii et al. 2015, Kucera and Cervinkova 2014, Takahashi et al. 2012). Moreover, dietary models, such as high fat- and fructose-fed models, are well known as NAFLD/NASH models (Takahashi et al. 2012). Recently, a NASH-derived hepatocellular carcinoma (HCC) model (STAM model) was reported by Fujii et al. (2013). The STAM model fulfills criteria for HCC diagnoses and demonstrates the following features: having at least 4 detectable tumor nodules, an average tumor growth rate of $150 \%$ from 16 to 20 weeks of age, no visible metastases, and relatively preserved liver function (Takakura et al. 2014).

In this study, we investigated the pathophysiological changes observed in hepatic lesions during the early stages in STAM mice by comparing this model with mice fed a high fat diet and/or treated with streptozotocin (STZ).

\section{Materials and Methods}

\section{Animals and chemicals}

This experiment was conducted in compliance with the Guidelines for Animal Experimentation at biological/pharmacological research laboratories of Japan Tobacco. Pathogen-free pregnant C57BL/6J mice (CLEA Japan, Tokyo, Japan) at 14 days of age were purchased, and male pups were used in this study. Four groups: the STAM group, high fat diet-fed (HFD) group, STZ-treated (STZ) group, and normal group, were prepared.

Hepatic lesions in the STAM group were induced by a single subcutaneous injection of $200 \mu \mathrm{g}$ of STZ (Sigma, MO, USA) 2 days after birth followed by feeding with a $32 \%$ fat high-fat diet (HFD32; CLEA Japan, Tokyo, Japan) ad libitum after 4 weeks of age. Mice in the HFD group were fed the high-fat diet (HFD32) after 4 weeks of age. In mice in the STZ group, a single subcutaneous injection of $200 \mu \mathrm{g}$ of STZ was administered 2 days after birth. Mice in the normal group were fed a standard diet (CRF-1, Charles River Japan, Yokohama, Japan). The mice were housed in a climatecontrolled room with a temperature of $23 \pm 3{ }^{\circ} \mathrm{C}$, humidity $55 \pm 15 \%$, and a 12 -h dark-light cycle.

\section{Biochemical parameters}

Body weight and biochemistry parameters in the blood were monitored at 5, 7, and 10 weeks of age. Blood samples were collected from the orbital venous plexus under non-fasting conditions. Glucose, triglycerides (TG), total cholesterol (TC), alanine aminotransferase (ALT), and aspartate aminotransferase (AST) levels were measured using commercial kits (Roche Diagnostics, Basel, Switzerland) and an automatic analyzer (Hitachi 7180; Hitachi High-Technologies, Tokyo, Japan). Commercial ELISA kits were used to measure serum insulin (Rat Insulin ELISA Kit; Morinaga Institute of Biological Science, Yokohama, Japan).

\section{Tissue sampling and histopathology}

Necropsy was performed at 5,7 , and 10 weeks of age. All animals were sacrificed by exsanguination under isoflurane anesthesia. The livers were sampled for gene expression, hepatic lipid content, and histopathological analysis. Samples for gene expression and hepatic lipid content analyses were stored at $-80^{\circ} \mathrm{C}$ until testing. For histopathological examinations, the livers were immediately fixed in $10 \%$ formalin neutral buffer solution $(\mathrm{v} / \mathrm{v}$, formaldehyde: 1 , phosphate buffer: 9, pH 7.4). After resection, the tissues were paraffin-embedded using standard techniques and thinsectioned $(3$ to $5 \mu \mathrm{m}$ ). The sections were stained with hematoxylin and eosin (HE) and Sirius Red. These samples were all examined histopathologically, and findings were graded from normal (-) to severe $(+++)$. Immunohistochemical analysis of hexanoyl-lysine (HEL) regarding the oxidative stress, malignancy and fibrosis were performed in the liver section from 5 weeks of age in all groups. Staining was visualized using DAB Peroxidase Substrate kit (JalCA, Sizuoka, Japan) to produce a brown reaction product indicating antigen localization. Anti-mouse Hexanoyl-Lysine adduct (HEL, JalCA, Sizuoka, Japan) was used for immunochemical detection of hepatocyte in liver.

\section{Hepatic TG and TC content}

A portion of the liver weighing approximately $100 \mathrm{mg}, 0.5 \mathrm{ml}$ of methanol, and zirconia beads were added to tubes. The liver portion was homogenized using a mixer mill (MM300 Retsch) $(25 \mathrm{~Hz}, 10 \mathrm{~min})$. To the homogenized solution, $1 \mathrm{ml}$ of chloroform was added and mixed thoroughly. The mixture was then centrifuged $\left(10000 \times \mathrm{g}, 5 \mathrm{~min}, 4{ }^{\circ} \mathrm{C}\right)$ and the resulting supernatant collected. Solvents contained in $0.5 \mathrm{ml}$ of the supernatant 
were dried under a stream of nitrogen gas. To the residue, $0.5 \mathrm{ml}$ of 2-propanol was added, and the residue was subsequently dissolved again. TG and TC concentrations in the 2-propanol solution were determined using the biochemistry automatic analyzer (Hitachi 7170S; Hitachi, Tokyo, Japan).

\section{$m R N A$ quantification with real-time quantitative PCR}

Total RNA was extracted from the livers of animals at 5, 7, and 10 weeks of age. RNA was transcribed into cDNA using M-MLV reverse transcriptase and random primers (Invitrogen, Carlsbad, $\mathrm{CA})$. The reaction mixture was incubated for $10 \mathrm{~min}$ at $25^{\circ} \mathrm{C}, 1 \mathrm{~h}$ at $37^{\circ} \mathrm{C}$, and $5 \mathrm{~min}$ at $95^{\circ} \mathrm{C}$. Real-time PCR quantification was performed in a $50-\mu 1$ reaction mixture with an automated sequence detector combined with ABI Prism 7700 Sequence Detection System software (Applied Biosystems, Foster City, CA). The reaction mixture contained $50 \mathrm{ng}$ of synthesized cDNA, $3.5 \mathrm{mM}$ $\mathrm{MgCl}_{2}, 0.3 \mu \mathrm{M}$ primers, $0.1 \mu \mathrm{M}$ probes, and 1.25 units of Ampli Taq Gold $\AA$. Cycle parameters were $10 \mathrm{~min}$ at $95^{\circ} \mathrm{C}$, followed by 40 cycles of $15 \mathrm{~s}$ at $95^{\circ} \mathrm{C}$ and $60 \mathrm{~s}$ at $60{ }^{\circ} \mathrm{C}$. The following primer and FAM-conjugated probe were designed using Primer Express software (Applied Biosystems): Tumor Necrosis Factor $\alpha$ (TNF $\alpha)$ :

Forward:

AGACCCTCACACTCAGATCATCTTC;

Reverse:

ACTTGGTGGTTTGCTACGACG; Probe:

CAAAATTCGAGTGACAAGCCTGTAGCCC), and $\beta$-actin (purchased from Applied Biosystems). The expression of Tissue Inhibitor of Metalloproteinase 1 (TIMP) (Mm0041818_m1) was confirmed using Taqman Gene Expression Assays.

\section{Statistical analysis}

The results of biological parameters are expressed as the mean \pm standard deviation (SD). Statistical analyses of differences between mean values were performed using a Tukey Kramer test. Differences were considered significant at $\mathrm{p}<0.05$.

\section{Results}

The STAM group showed decreases in body weight and blood insulin levels in comparison with the normal group, and mice in the HFD group showed obesity and hyperinsulinemia in comparison with the STAM group during the experimental period (Body weight at 10 weeks of age: HFD, $37.5 \pm 3.5 \mathrm{~g}$ vs. STAM, $21.1 \pm 1.9 \mathrm{~g}$, Blood insulin level at 10 weeks of age: HFD, $2.54 \pm 0.86 \mathrm{ng} / \mathrm{ml}$ vs. STAM, $0.33 \pm 0.13 \mathrm{ng} / \mathrm{ml}$ ) (Figs $1 \mathrm{~A}$ and $1 \mathrm{C}$ ). Mice in both the STAM and STZ groups showed significant hyperglycemia from 5 weeks of age (STAM, $594.3 \pm 108.3 \mathrm{mg} / \mathrm{dl}, \mathrm{STZ}, 472.5 \pm 126.3 \mathrm{mg} / \mathrm{dl}$, HFD, $253.5 \pm 15.0 \mathrm{mg} / \mathrm{dl}$ ), and the hyperglycemia was sustained during the experimental period (Fig. 1B). Blood TG and TC levels in the STZ group gradually increased in comparison with the normal group during the experimental period. Blood TC levels in the HFD group also increased over time; however, TG levels did not change in comparison with the normal group during the experimental period (Figs 1D and 1E). Blood ALT levels in the STAM and STZ groups significantly increased at 5 or 7 weeks of age in comparison with the normal group, and the level in the HFD group tended to increase, although this increase was not significant (Fig. 1F). Changes in blood AST levels followed a similar pattern as blood ALT levels (data not shown).

Relative liver weights in the STAM group showed significant increases during the experimental period, and the weights in the STZ group showed significant increases at 7 and 10 weeks of age in comparison with the normal group; however, the weights in the HFD group did not show increases in comparison with the normal group (Fig. 2A). Hepatic TG content in the STAM and HFD groups showed significant increases in comparison with the normal group during the experimental period, and $\mathrm{TC}$ content also showed an increase or a tendency to increase (Figs $2 \mathrm{~B}$ and 2C). Mice in the STZ group did not show significant increases in hepatic lipid content. Changes in the mRNA expression of TNF $\alpha$, an inflammation related factor, and TIMP1, a fibrosis related factor, were determined for each group (Figs 2D and 2E). Both TNFa and TIMP1 mRNA expression in the HFD and STZ groups showed a tendency to increase in comparison with the normal group; however, the changes were not significant. TNF $\alpha$ and TIMP1 mRNA expression in the STAM group also showed a tendency to increase in comparison with the normal group, and TNF $\alpha$ expression at 10 weeks of age significantly increased in comparison with the normal group (Fig. 2D). 


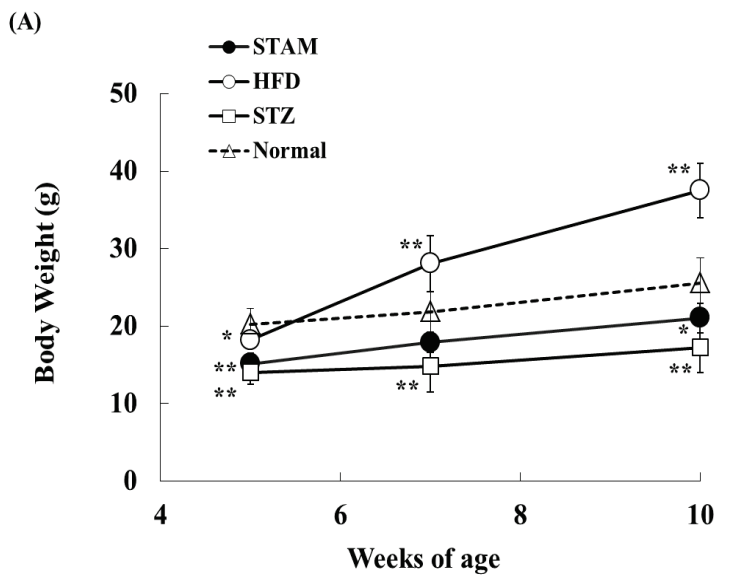

(B)

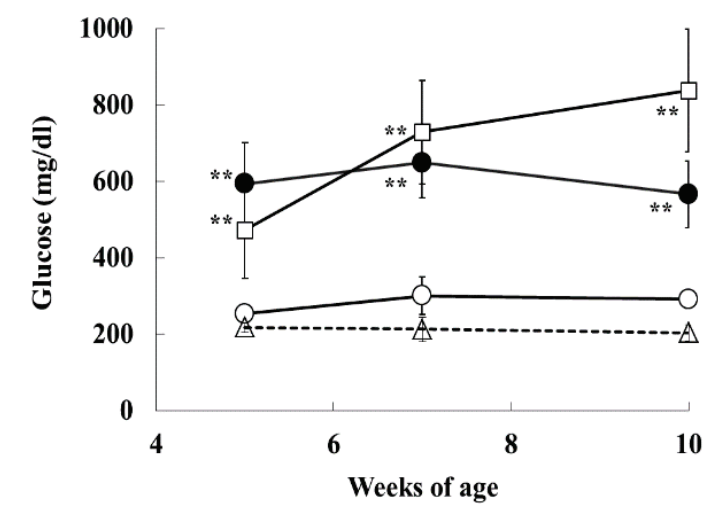

(C)

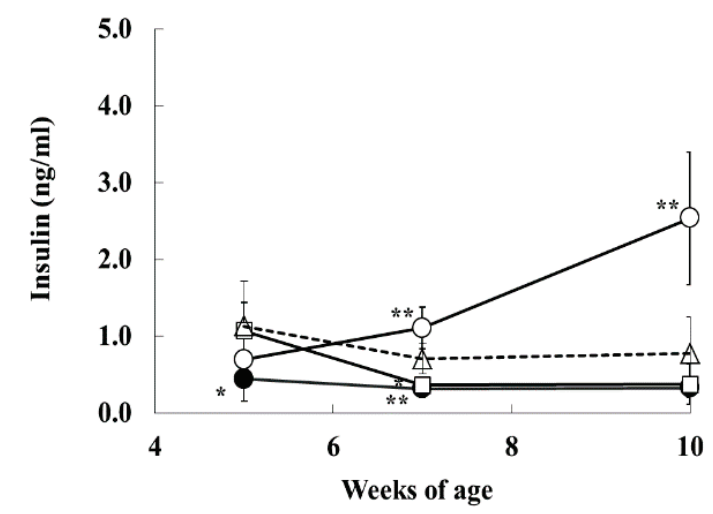

(D)

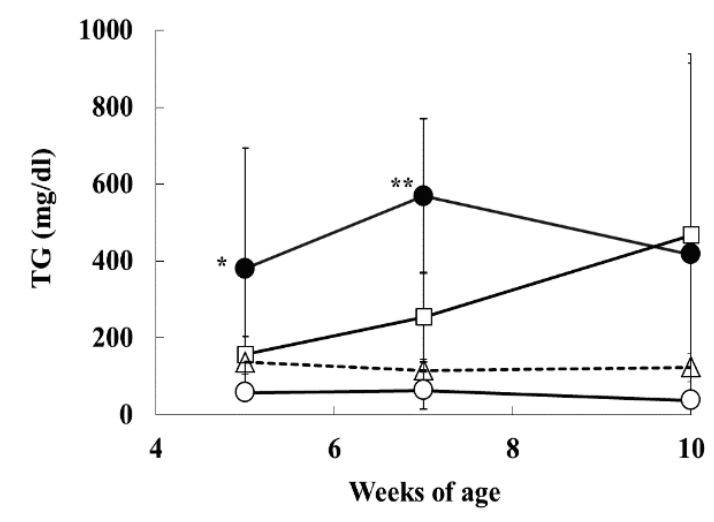

(E)

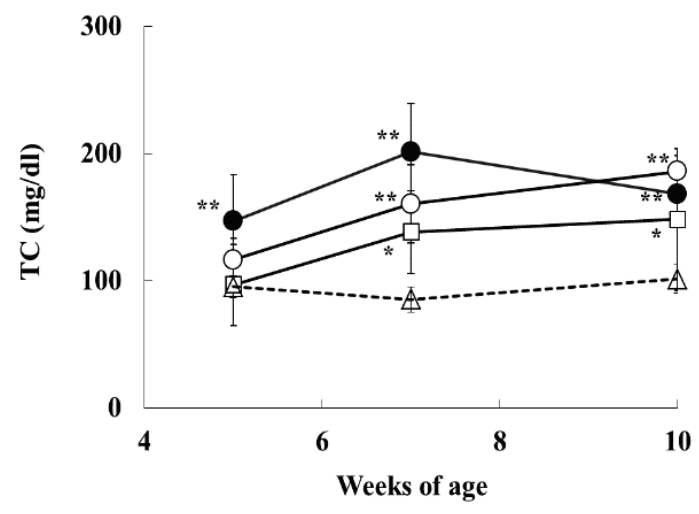

(F)

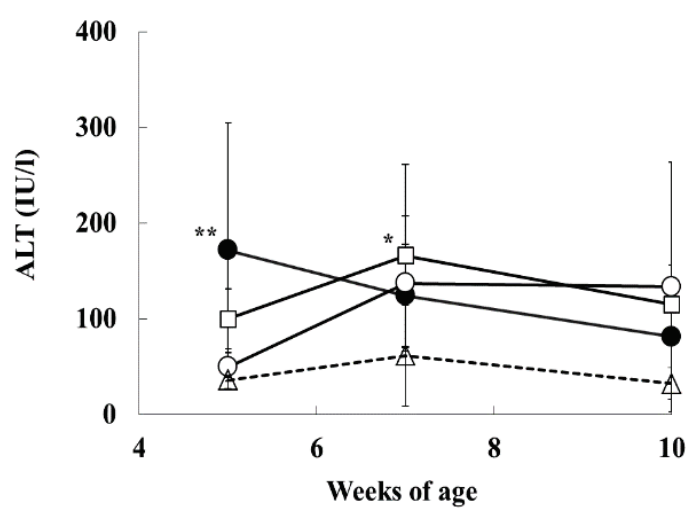

Fig. 1. Changes in body weight and biochemistry parameters in STAM, HFD, STZ, and Normal groups. (A): Body weight; (B): Glucose; (C): Insulin; (D): TG; (E): TC; (F): ALT. Data represent means \pm SD ( $n=7-8) .{ }^{*} p<0.05,{ }^{*} * p<0.01$; significantly different from the Normal group.

Liver histopathologies were examined by HE staining, and Sirius Red staining to evaluate fibrosis (Table 1, Figs 3 and 4). In STAM mice, moderate or severe changes in hepatosteatosis were observed from 5 weeks of age, and moderate or severe changes in hypertrophic hepatocytes from 7 weeks of age and significant changes in fibrosis were observed until 10 weeks of age. In mice in the HFD group, slight hepatosteatosis was observed from 5 weeks of age, and moderate or severe changes in hypertrophic hepatocytes were observed at 10 weeks of age. Moreover, the fibrosis in the HFD group was observed from 7 weeks of age. In 

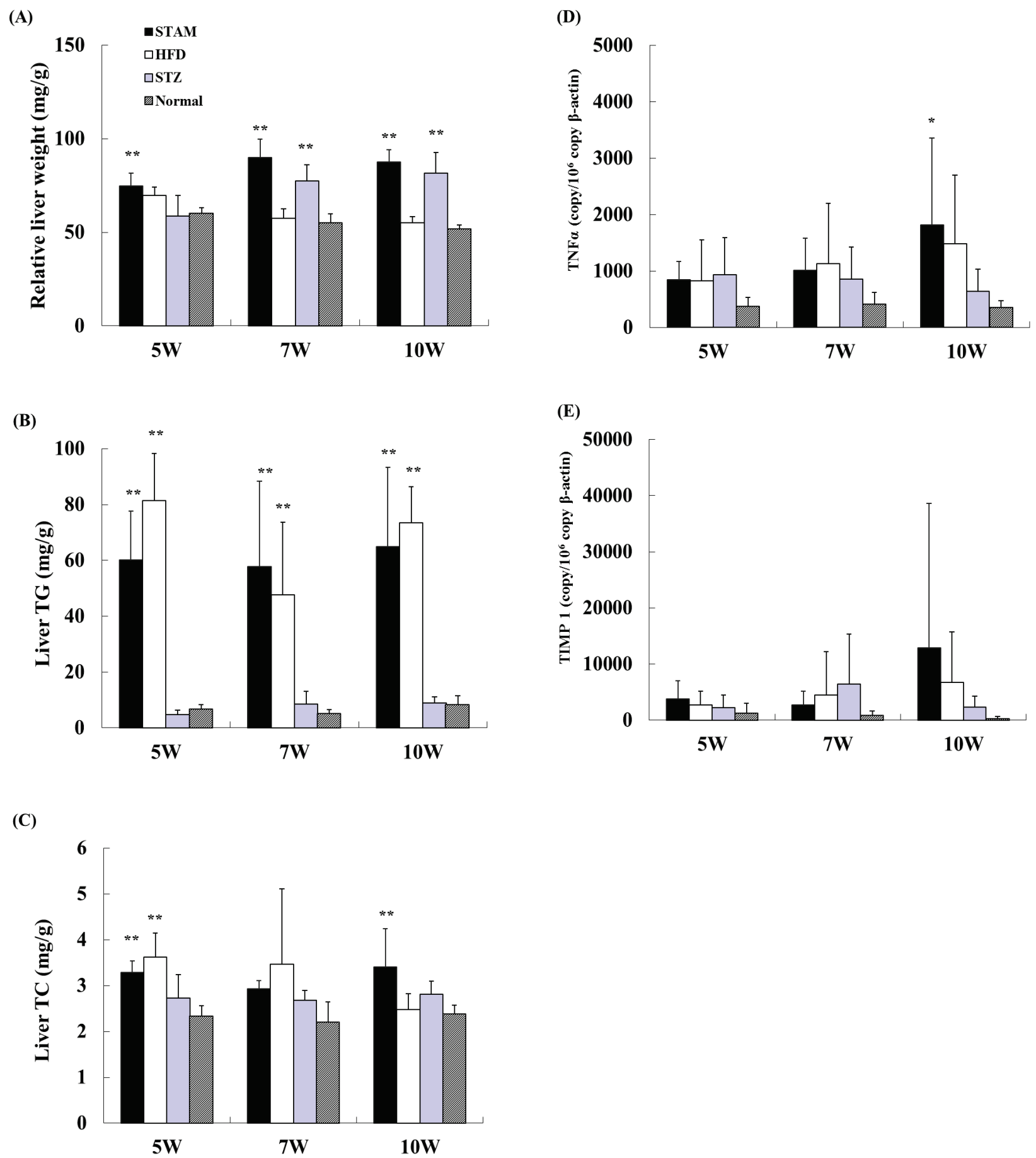

Fig. 2. Changes in liver weight (A), hepatic TG (B) and TC (C) content, and hepatic TNFa (D) and TIMP1 (E) mRNA expression in STAM, HFD, STZ, and Normal groups. Data represent means \pm SD $(n=7-8)$. $* p<0.05, * * p<0.01$; significantly different from the Normal group.

mice in the STZ group, the hepatic fibrosis was observed from 5 weeks of age ( 6 mice in 8 mice), and very slight changes in hepatosteatosis and hypertrophic hepatocytes were observed at 10 weeks of age. In immunohisto- chemical examinations, HEL, an indicator of oxidative stress, positive cells were detected in tissues of the STZ group, but not detected in the normal group (Figs 3I-3L). 
Table 1. Histopathological findings in livers from 4 groups using C57BL6 mice.

\begin{tabular}{|c|c|c|c|c|c|c|c|c|c|c|c|c|c|c|c|c|c|c|c|c|c|c|c|c|}
\hline \multirow[b]{3}{*}{ Animal No. } & \multicolumn{24}{|c|}{ STAM group } \\
\hline & \multicolumn{8}{|c|}{5 weeks of age } & \multicolumn{8}{|c|}{7 weeks of age } & \multicolumn{8}{|c|}{10 weeks of age } \\
\hline & 1 & 2 & 3 & 4 & 5 & 6 & 7 & 8 & 9 & 10 & 11 & 12 & 13 & 14 & 15 & $\mathbf{M N}$ & 17 & 18 & 19 & 20 & 21 & 22 & 23 & 24 \\
\hline $\begin{array}{l}\text { Hepatosteatosis (fatty } \\
\text { change) } \\
\text { Hypertrophy hepatocyte }\end{array}$ & $2+$ & $2+$ & + & $2+$ & $3+$ & $2+$ & $2+$ & + & $2+$ & + & + & $2+$ & $3+$ & $2+$ & + & & $2+$ & $3+$ & $2+$ & $3+$ & + & $3+$ & $2+$ & $2+$ \\
\hline $\begin{array}{l}\text { (vacuolation/fatty } \\
\text { change) }\end{array}$ & + & + & \pm & \pm & $2+$ & + & + & + & $2+$ & + & $2+$ & $2+$ & $2+$ & $2+$ & $2+$ & & $2+$ & $3+$ & $2+$ & $3+$ & + & $2+$ & $2+$ & $2+$ \\
\hline Fibrosis & \pm & \pm & \pm & \pm & + & \pm & \pm & \pm & + & \pm & \pm & - & \pm & \pm & + & & \pm & + & \pm & $2+$ & + & \pm & + & + \\
\hline
\end{tabular}

\begin{tabular}{|c|c|c|c|c|c|c|c|c|c|c|c|c|c|c|c|c|c|c|c|c|c|c|c|c|}
\hline \multirow[b]{3}{*}{ Animal No. } & \multicolumn{24}{|c|}{ HFD group } \\
\hline & \multicolumn{8}{|c|}{5 weeks of age } & \multicolumn{8}{|c|}{7 weeks of age } & \multicolumn{8}{|c|}{10 weeks of age } \\
\hline & 25 & 26 & 27 & 28 & 29 & 30 & 31 & 32 & 33 & 34 & 35 & 36 & 37 & 38 & 39 & 40 & 41 & 42 & 43 & 44 & 45 & 46 & 47 & 48 \\
\hline $\begin{array}{l}\text { Hepatosteatosis (fatty } \\
\text { change) }\end{array}$ & + & + & + & + & + & + & \pm & $2+$ & - & + & + & $3+$ & + & $2+$ & + & + & $2+$ & $2+$ & $3+$ & $3+$ & $3+$ & $3+$ & $3+$ & $2+$ \\
\hline $\begin{array}{l}\text { Hypertrophy hepatocyte } \\
\text { (vacuolation/fatty } \\
\text { change) }\end{array}$ & - & \pm & - & \pm & - & - & - & \pm & - & - & \pm & + & - & \pm & \pm & - & + & + & $2+$ & $2+$ & $2+$ & $2+$ & $3+$ & + \\
\hline Fibrosis & - & - & - & - & - & - & - & - & \pm & + & - & + & - & - & - & \pm & - & - & \pm & \pm & + & \pm & - & \pm \\
\hline
\end{tabular}

\begin{tabular}{|c|c|c|c|c|c|c|c|c|c|c|c|c|c|c|c|c|c|c|c|c|c|c|c|c|}
\hline \multirow[b]{3}{*}{ Animal No. } & \multicolumn{24}{|c|}{ STZ group } \\
\hline & \multicolumn{8}{|c|}{5 weeks of age } & \multicolumn{8}{|c|}{7 weeks of age } & \multicolumn{8}{|c|}{10 weeks of age } \\
\hline & 49 & 50 & 51 & 52 & 53 & 54 & 55 & 56 & 57 & 58 & 59 & 60 & 61 & MN & 63 & 64 & 65 & 66 & 67 & 68 & 69 & 70 & 71 & 72 \\
\hline $\begin{array}{l}\text { Hepatosteatosis (fatty } \\
\text { change) } \\
\text { Hypertrophy hepatocyte }\end{array}$ & - & - & \pm & - & \pm & - & - & - & - & - & - & \pm & - & & \pm & \pm & - & \pm & \pm & \pm & \pm & \pm & - & \pm \\
\hline $\begin{array}{l}\text { (vacuolation/fatty } \\
\text { change) }\end{array}$ & - & - & \pm & - & - & \pm & - & - & \pm & \pm & \pm & \pm & - & & \pm & \pm & \pm & \pm & \pm & \pm & + & \pm & - & \pm \\
\hline Fibrosis & \pm & + & \pm & - & \pm & - & + & \pm & + & \pm & \pm & + & \pm & & - & - & - & \pm & - & \pm & \pm & \pm & + & + \\
\hline
\end{tabular}

\begin{tabular}{|c|c|c|c|c|c|c|c|c|c|c|c|c|c|c|c|c|c|c|c|c|c|c|c|c|}
\hline \multirow[b]{3}{*}{ Animal No. } & \multicolumn{24}{|c|}{ Normal group } \\
\hline & \multicolumn{8}{|c|}{5 weeks of age } & \multicolumn{8}{|c|}{7 weeks of age } & \multicolumn{8}{|c|}{10 weeks of age } \\
\hline & 73 & 74 & 75 & 76 & 77 & 78 & 79 & 80 & 81 & 82 & 83 & 84 & 85 & MN & 87 & 88 & 89 & 90 & 91 & MN & 93 & 94 & 95 & 96 \\
\hline $\begin{array}{l}\text { Hepatosteatosis (fatty } \\
\text { change) } \\
\text { Hypertrophy hepatocyte }\end{array}$ & - & - & - & - & - & - & - & - & - & - & - & - & - & & - & - & - & - & - & & - & - & - & - \\
\hline $\begin{array}{l}\text { (vacuolation/fatty } \\
\text { change) }\end{array}$ & - & - & - & - & - & - & - & - & - & - & - & - & - & & - & - & - & - & - & & - & - & - & - \\
\hline Fibrosis & - & - & - & - & - & - & - & - & - & - & - & \pm & - & & - & - & - & - & - & & - & - & - & - \\
\hline
\end{tabular}

Grade: \pm Very slight, + Slight, 2+ Moderate, 3+ Severe. MN: missing number. Fibrosis was evaluated using Sirius red staining.

\section{Discussion}

Recently, the incidence of NAFLD has increased worldwide with the increased prevalence of obesity, type 2 diabetes, and dyslipidemia, and approximately $10 \%$ of NAFLD patients develop NASH, in which hepatic steatosis is related to inflammation and hepatocyte apoptosis (Bugianesi et al. 2002, Clark 2006, Day and James 1998). Furthermore, NASH leads to fibrosis, liver cirrhosis, and eventually hepatocellular carcinoma. According to the two-hit hypothesis for NASH progression, the first hit is lipid accumulation in hepatocytes via metabolic disorders, and the second hit is a combination of multiple factors, including genetics, insulin resistance, oxidative stress, and inflammation (Day and James 1998, Dowman et al. 2010). However, the precise mechanism for the progression from hepatic steatosis to NASH has yet to be elucidated.

Several animal models have been developed to understand the pathogenesis of NAFLD/NASH. The STAM model is the first animal model that is a NASH-derived HCC model expected to establish pharmacological intervention against HCC (Fujii et al. 2013, Takakura et al. 2014). HCC in the STAM model is reportedly equivalent to stages $\mathrm{B}$ to $\mathrm{C}$ disease classified in accordance with the Barcelona Clinic Liver Cancer staging system for humans (Takakura et al. 2014). We investigated the pathophysiological features of early hepatic lesions, from hepatic steatosis to fibrosis, by comparing the onset of lesions and progression among three groups, the STAM group, HFD group, and STZ group. 

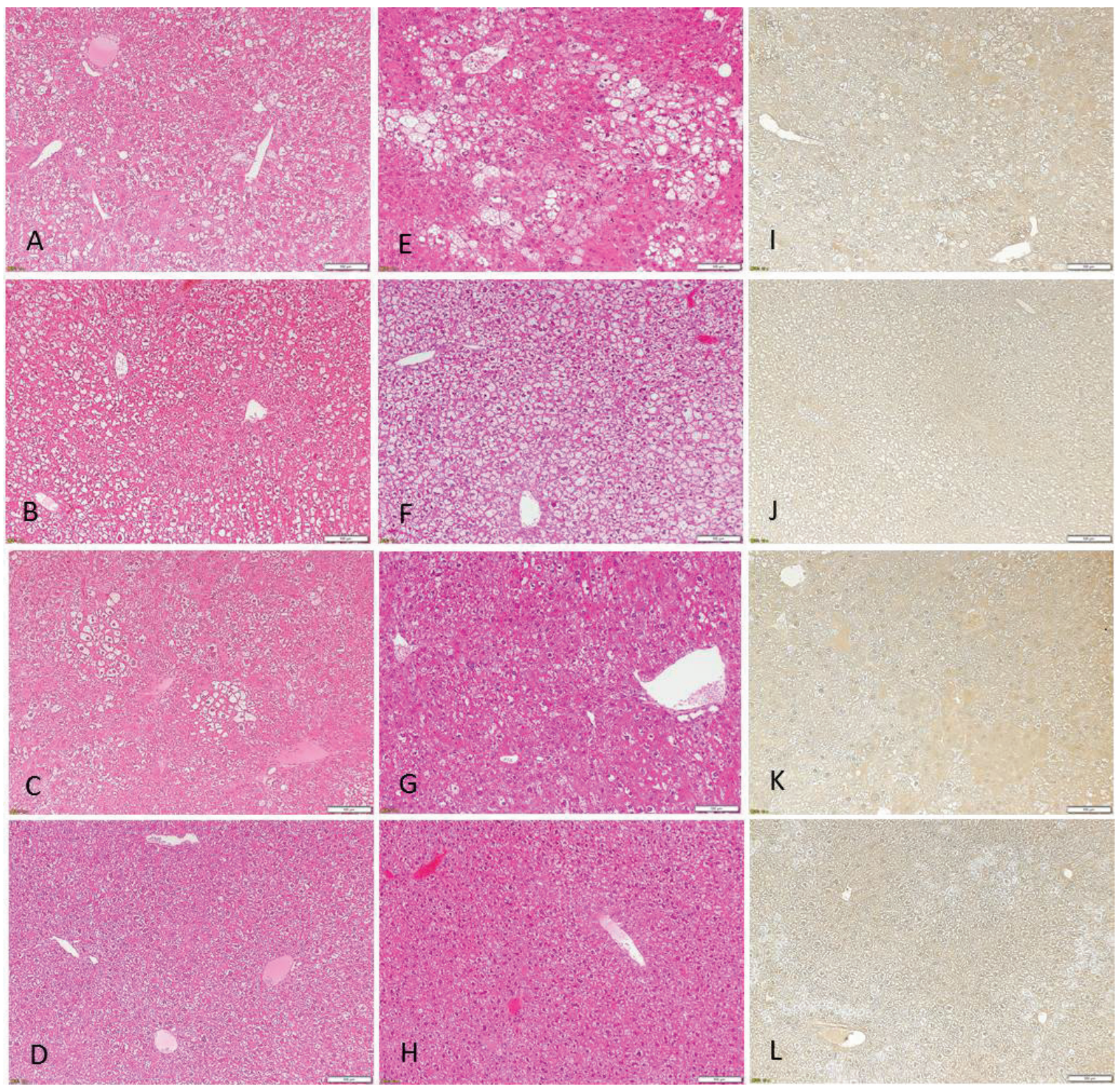

Fig. 3. Liver histopathology at 5 and 10 weeks of age. (A, E): STAM group; (B, F): HFD group; (C, G): STZ group; (D, H): Normal group. Hematoxylin and eosin (HE) staining. Bar $=100 \mu \mathrm{m}$. Immunohistochemistry of hexanoyl-lysine (HEL) in the liver at 5 weeks of age. (I): STAM group; (J): HFD group; (K) STZ group; (L): Normal group. Bar=100 $\mu \mathrm{m}$.

In comparison of histopathological findings in livers among three groups, hepatosteatosis, hypertrophy hepatocyte, and fibrosis were observed from 5 weeks of age in the STAM group; however, the fibrosis was not observed at 5 weeks of age in the HFD group. On the other hand, the fibrosis was observed from 5 weeks of age in the STZ group with the increase of blood glucose level. Moreover, the changes of hepatosteatosis and hypertrophy hepatocyte in the HFD group were enhanced periodically from 5 to 10 weeks of age; however those changes in the STZ group were very slight at 10 weeks of age.

In this study, the STAM group showed hepatic lesions, such as hepatosteatosis, hypertrophic hepatocytes, and fibrosis, as previously reported. STZ group showed significant hyperglycemia and hepatic fibrosis at 5 weeks of age; however, the HFD group did not show fibrosis at 5 weeks of age. Moreover, the oxidative stress marker of HEL was detected in the hepatocytes of animals in the STZ group, and inflammation-related mRNA also tended to increase at 5 weeks of age. Initial hepatic lesions, including fibrosis, in STAM mice are considered to be caused by oxidative stress with sustained hyperglycemia. Chronic hyperglycemia reportedly leads to the production of 
reactive oxygen species (ROS) and oxidative stress. Hyperglycemia induces the overproduction of NADH and mitochondrial ROS that inhibit glyceraldehyde 3-phosphate dehydrogenase (GAPDH) activity (Giacco and Brownlee 2010, Paradies et al. 2014, Yan 2014). The oxidative stress is considered to be an important factor in causing lethal hepatocyte injury associated with NAFLD/NASH. ALT levels at 5 weeks of age in the STZ group tended to increase, and the inflammation may be induced by oxidative stress. The increase of TIMP1 may also be associated with the development of hepatic fibrosis. High glucose reportedly increases the expression of mRNA and protein of matrix metallopeptidase 1 (MMP1) (Yang et al. 2009). Overt hyperglycemia was observed at 10 weeks of age in the STZ group. Carbohydrate content in the diet (crude fat, $32 \%$ and nitrogen free extracts, $29.4 \%$ in the high-fat diet vs. crude fat, $5.4 \%$ and nitrogen free extracts, $55.3 \%$ in the standard diet) and/or the food intake pattern may be related with the significant increase of blood glucose levels. It is necessary to pay attention to background of hyperglycemia at 10 weeks of age in the STZ group.

Mice in the HFD group showed obesity, hyperinsulinemia, and hypercholesterolemia, and these changes enhanced over time. Furthermore, the HFD group showed significant increases in lipid accumulation in the liver. Obesity, insulin resistance, and dyslipidemia are major factors that affect the development from hepatic steatosis to NASH (de Alwis and Day 2008). Insulin resistance is related with overt fat accumulation in ectopic tissues, such as the liver, and increased circulatory free fatty acids, which promote inflammation and endoplasmic reticulum stress, leading to fibrosis (Asrih and Jornayvaz 2015). It is reported that changes of hepatic lipid profiles, such as increases in acylcarnitine and diacylglycerol levels, were observed in STAM mice toward the fibrosis stage (Saito et al. 2015). Qualitative changes in hepatic lipids are also related with the development from hepatic steatosis to NASH.

In conclusion, increases in oxidative stress with hyperglycemia triggered hepatic lesions in STAM mice, and insulin resistance promoted lesion formation with hepatic lipid accumulation, leading to NASH. STAM mice may be a useful model for elucidating the pathogenesis of NASH with diabetes.

\section{Conflict of Interest}

All authors are employees of Japan Tobacco Inc.
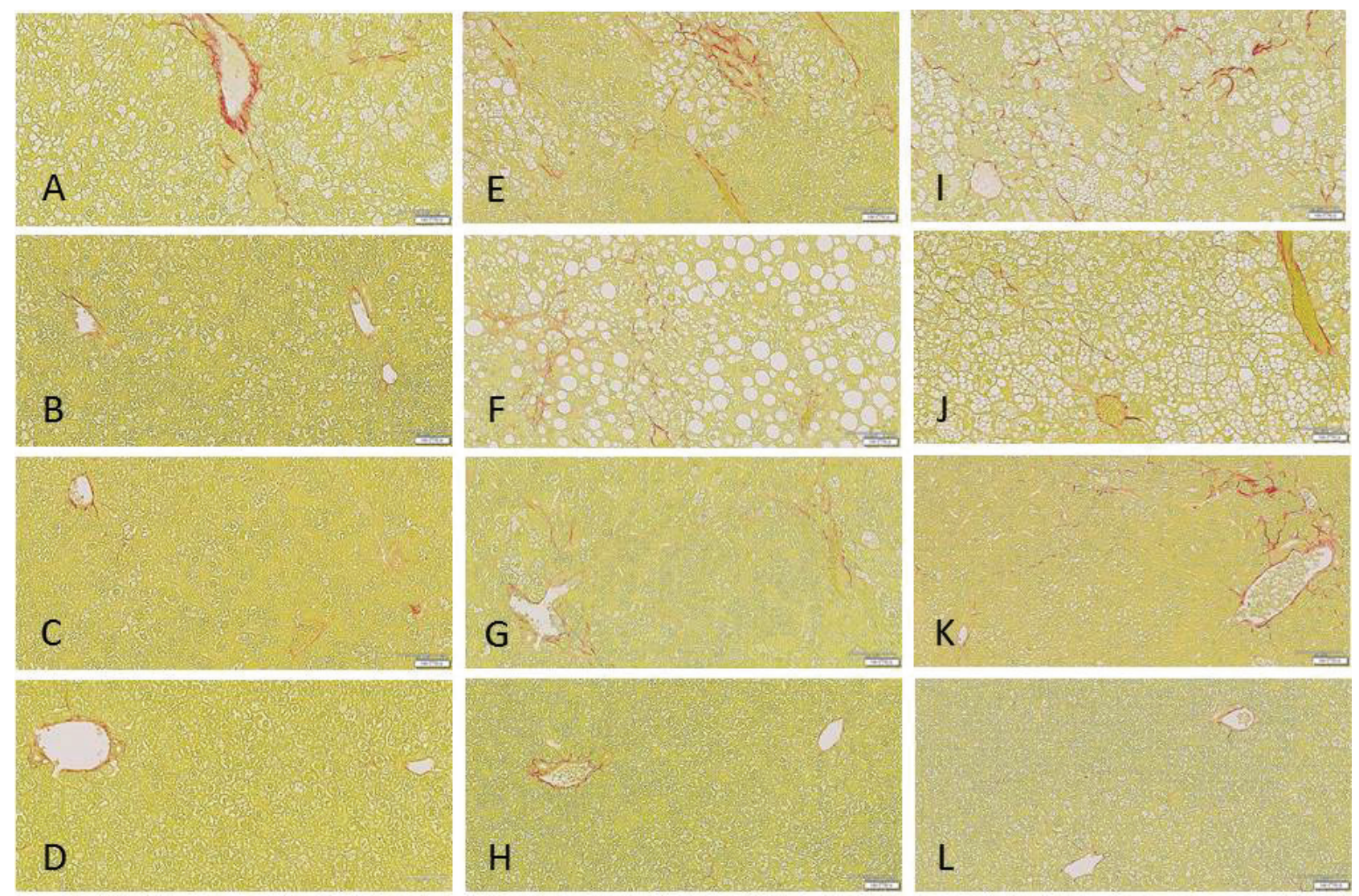

Fig. 4. Sirius Red staining in the liver at 5, 7 and 10 weeks of age. (A, E and I): STAM group; (B, F and J): HFD group; (C, G and K): STZ group; (D, H and L): Normal group. Bar $=100 \mu \mathrm{m}$. 


\section{References}

ASRIH M, JORNAYVAZ FR: Metabolic syndrome and nonalcoholic fatty liver disease: Is insulin resistance the link? Mol Cell Endocrinol 418: 55-65, 2015.

BUGIANESI E, LEONE N, VANNI E, MARCHESINI G, BRUNELLO F, CARUCCI P, MUSSO A, DE PAOLIS P, CAPUSSOTTI L, SALIZZONI M, RIZZETTO M: Expanding the natural history of nonalcoholic steatohepatitis: from cryptogenic cirrhosis to hepatocellular carcinoma. Gastroenterology 123: 134-140, 2002.

CLARK JM: The epidemiology of nonalcoholic fatty liver disease in adults. J Clin Gastroenterol 40 (Suppl 1): S5-S10, 2006.

DAY CP, JAMES OF: Steatohepatitis: a tale of two "hits"? Gastroenterology 114: 842-845, 1998.

DE ALWIS NM, DAY CP: Non-alcoholic fatty liver disease: the mist gradually clears. J Hepatol 48 (Suppl 1): S104-S112, 2008.

DOWMAN JK, TOMLINSON JW, NEWSOME PN: Pathogenesis of non-alcoholic fatty liver disease. QJM 103: 71-83, 2010.

ERTLE J, DECHENE A, SOWA JP, PENNDORF V, HERZER K, KAISER G, SCHLAAK JF, GERKEN G, SYN WK, CANBAY A: Non-alcoholic fatty liver disease progresses to hepatocellular carcinoma in the absence of apparent cirrhosis. Int J Cancer 128: 2436-2443, 2011.

FALCK-YTTER Y, YOUNOSSI ZM, MARCHESINI G, MCCULLOUGH AJ: Clinical features and natural history of nonalcoholic steatosis syndromes. Semin Liver Dis 21: 17-26, 2001.

FUJII M, SHIBAZAKI Y, WAKAMATSU K, HONDA Y, KAWAUCHI Y, SUZUKI K, ARUMUGAM S, WATANABE K, ICHIDA T, ASAKURA H, YONEYAMA H: A murine model for non-alcoholic steatohepatitis showing evidence of association between diabetes and hepatocellular carcinoma. Med Mol Morphol 46: 141-152, 2013.

GIACCO F, BROWNLEE M: Oxidative stress and diabetic complications. Circ Res 107: 1058-1070, 2010.

GREENFIELD V, CHEUNG O, SANYAL AJ: Recent advances in nonalcholic fatty liver disease. Curr Opin Gastroenterol 24: 320-327, 2008.

ISHII Y, MOTOHASHI Y, MURAMATSU M, KATSUDA Y, MIYAJIMA K, SASASE T, YAMADA T, MATSUI T, KUME S, OHTA T: Female spontaneously diabetic Torii fatty rats develop nonalcoholic steatohepatitis-like hepatic lesions. World J Gastroenterol 21: 9067-9078, 2015.

KUCERA O, CERVINKOVA Z: Experimental models of non-alcoholic fatty liver disease in rats. World J Gastroenterol 20: 8364-8376, 2014.

PARADIES G, PARADIES V, RUGGIERO FM, PETROSILLO G: Oxidative stress, cardiolipin and mitochondrial dysfunction in nonalcoholic fatty liver disease. World J Gastroenterol 20: 14205-14218, 2014.

SAITO K, UEBANSO T, MAEKAWA K, ISHIKAWA M, TAGUCHI R, NAMMO T, NISHIMAKI-MOGAMI T, UDAGAWA H, FUJII M, SHIBAZAKI Y, YONEYAMA H, YASUDA K, SAITO Y: Characterization of hepatic lipid profiles in a mouse model with nonalcoholic steatohepatitis and subsequent fibrosis. Sci Rep $\mathbf{5}$ : 12466, 2015.

TAKAHASHI Y, SOEJIMA Y, FUKUSATO T: Animal models of nonalcoholic fatty liver disease/nonalcoholic steatohepatitis. World J Gastroenterol 18: 2300-2308, 2012.

TAKAKURA K, KOIDO S, FUJII M, HASHIGUCHI T, SHIBAZAKI Y, YONEYAMA H, KATAGI H, KAJIHARA M, MISAWA T, HOMMA S, OHKUSA T, TAJIRI H: Characterization of non-alcoholic steatohepatitis-derived hepatocellular carcinoma as a human stratification model in mice. Anticancer Res 34: 4849-4855, 2014.

YAN LJ: Pathogenesis of chronic hyperglycemia: from reductive stress to oxidative stress. J Diabetes Res 2014: 137919, 2014.

YANG J, ZHOU Q, WANG Y, LIU K, ZHANG J: Effect of high glucose on PKC and MMPs/TIMPs in human mesangial cells (Article in Cinese). Zhong Nan Da Хие Хие Bao Yi Xиe Ban 34: 425-431, 2009.

ZELBER-SAGI S, NITZAN-KALUSKI D, HALPERN Z, OREN R: Prevalence of primary non-alcoholic fatty liver disease in a population-based study and its association with biochemical and anthropometric measures. Liver Int 26: 856-863, 2006. 